\title{
openheart Copper deficiency may be a leading cause of ischaemic heart disease
}

\author{
James J DiNicolantonio, ${ }^{1}$ Dennis Mangan, ${ }^{2}$ James H O’Keefe ${ }^{3}$
}

To cite: DiNicolantonio JJ, Mangan D, O'Keefe JH. Copper deficiency may be a leading cause of ischaemic heart disease. Open Heart 2018;5:e000784. doi:10.1136/ openhrt-2018-000784

Accepted 22 August 2018

Check for updates

(c) Author(s) (or their employer(s)) 2018. Re-use permitted under CC BY-NC. No commercial re-use. See rights and permissions. Published by BMJ.

${ }^{1}$ Department of Preventive Cardiology, Mid America Heart Institute, Kansas, Missouri, USA

${ }^{2}$ Santa Rosa, Santa Rosa, California, USA

${ }^{3}$ Department of Preventive Cardiology, University of Missouri-Kansas City, Saint Lukes Mid America Heart Institute, Kansas City, Missouri, USA

Correspondence to Dr James J DiNicolantonio; jjdinicol@gmail.com

\section{INTRODUCTION}

The burden of ischaemic heart disease (IHD) continues to grow in the developed world with a greater fraction of the population composed of older people. In the USA, heart disease is the leading cause of death overall and in those over 65 years of age. ${ }^{1}$ The most accepted theory for the cause of IHD remains high total or elevated LDL cholesterol, which in turn is due to a high intake of dietary saturated fat; yet this theory has come under increasing scrutiny in recent years. Indeed, recent meta-analyses have found no relation between dietary saturated fat consumption and the incidence of IHD. ${ }^{2}$

We may have been looking in the wrong places in our attempts to discern the cause(s) of IHD. Copper is an essential trace element that has been an overlooked factor in IHD. Numerous animal and human studies have demonstrated that copper deficiency can cause IHD and that copper supplementation or adequate dietary copper can improve many of the risk factors for IHD. Copper deficiency could be driving much of the current burden of IHD in the population. Copper intakes have been declining and it appears that a large fraction of the population does not even consume the recommended daily allowance (RDA) for copper ${ }^{3}$ (0.9 mg per day) let alone an optimal intake of copper (2.6 mg per day). ${ }^{4}$ Thus, it appears that much of the population is at risk of inadequate but especially suboptimal intakes of copper.

Copper is involved in numerous biological processes, and its insufficiency or deficiency can to lead to many of the risks or manifestations of IHD, as we discuss below.

\section{Biological properties of copper}

Copper is involved in the functions of many copper-dependent proteins, including transcriptional regulators, chaperones, oxidoreductases, mitochondrial electron transport and free radical scavenging. ${ }^{5}$ Copper is also important for immune function. Low dietary copper intake reduces immune response, which is not restored to normal levels even after several weeks of a high copper intake. ${ }^{6}$

In relation to IHD, the heart is one of the main organs affected by copper deficiency, causing a reduction in metabolism and energy supply in the heart. ${ }^{7}$ Insufficient dietary copper can produce almost every risk factor for IHD. ${ }^{8}$ There are many important similarities between copper deficiency in animals and IHD in humans, including glucose intolerance, hypercholesterolemia, abnormal ECG, hyperuricemia and hypertension, all of which are risk factors for IHD. Much of the lipid hypothesis of heart disease can be seen in the light of copper deficiency. ${ }^{9}$

\section{Lipoproteins and copper}

The oxidation of low-density lipoproteins (LDLs) is thought to play a significant role in atherosclerosis. ${ }^{10}$ Copper deficiency increases the susceptibility of both LDL and other lipoproteins (high-density lipoprotein (HDL) and very-low-density lioprotein (VLDL)) to oxidation. ${ }^{11}$ Lipoproteins from copper-deficient animals show increased formation of thiobarbituric acid reactive substances when exposed to oxidative reactions using iron, which indicates that copper may exert a protective effect against iron-induced oxidation. While copper ions can catalyse the oxidation of lipoproteins, copper is also a necessary component of enzymes that prevent oxidative modification, such as copper, zinc superoxide dismutase. ${ }^{12}$ Copper-deficient animals also show increases in glycated haemoglobin, although lipoproteins do not appear to be more glycated than controls. ${ }^{13}$ The mechanisms behind increased lipoprotein oxidation are not known with certainty, but may be related to the physicochemical properties of the lipoproteins, to decreased levels of copper-dependent antioxidant enzymes or to other factors.

Copper deficiency can also cause hypercholesterolemia, one mechanism for this being increased levels of hydroxymethylglutaryl-coenzyme A (HMG-CoA) reductase, a 
key enzyme in the cholesterol synthesis pathway. Notably, statin drugs used in the prevention and treatment of IHD interfere with the activity of HMG-CoA reductase and thus lower cholesterol levels. Rats that were made copper-deficient had a $>50 \%$ increase in total cholesterol and an increase in HMG-CoA reductase activity of $85 \%$ to $288 \%$. $^{14}$

Copper deficiency can increase total cholesterol and increase the susceptibility of lipoproteins to oxidation, two key features that increase IHD risk. Dietary copper or copper supplementation may thus favourably impact these risk factors without any of the side effects often seen in drug treatment. Seen another way, perhaps high total cholesterol and oxidised lipoproteins seen in humans with increased IHD risk, or actual disease, are artefacts of lower body copper levels, which is the real risk factor.

Patients with hypercholesterolemia and supplemented with copper at $5 \mathrm{mg} /$ day for 45 days had a decrease in total cholesterol, LDL and triglycerides, and an increase in HDL cholesterol. ${ }^{15}$ The results suggest that perhaps around $40 \%$ of patients with hypercholesterolemia may have marginal copper deficiency, and that their condition could be treated with copper supplementation. In apparently healthy men with adequate copper status, copper supplementation had no effect on lipid profiles. ${ }^{16}$

In rats, a diet high in saturated fat increases cholesterol levels, with unsaturated fat having a protective effect. However, in copper-deficient animals, the level of dietary iron determines hyperlipidemia, not the type of dietary fat. ${ }^{17}$ The group of copper-deficient animals that were fed high-iron diets either died of ruptured hearts or developed severe anaemia, enlarged hearts and livers, hypercholesterolemia and elevated triglycerides. Thus, copper deficiency ties in with the iron hypothesis of heart disease, in which excess levels of stored body iron promote IHD. ${ }^{18}$ Normally benign levels of body iron may increase heart disease risk factors in the face of dietary copper deficiency. More importantly, copper deficiency can lead to hepatic iron overload and cirrhosis ${ }^{1920}$ with iron overload being treated by copper supplementation..$^{21}$ Iron overload also induces mild copper deficiency. ${ }^{22}$ The severity of copper deficiency can also be reduced with iron chelators. ${ }^{23}$ Thus, copper deficiency contributes to iron excess in the body and vice versa.

The ratio of zinc to copper may also be important in the production of hypercholesterolemia. In rats, high ratios of zinc to copper in drinking water resulted in higher plasma cholesterol. ${ }^{24}$ Inadequate copper intake in humans can also result in increased cholesterol levels even when intake is only slightly below the RDA $(0.83 \mathrm{mg}$ per day). ${ }^{25}$ In humans, copper supplementation of adult men at $2 \mathrm{mg}$ /day for 4 weeks increases levels of SOD and plasma diamine oxidase and significantly increases lag times for lipoprotein oxidation in those subjects with lower levels of stored body copper. ${ }^{26}$

\section{Antioxidant enzymes}

Superoxide dismutase (SOD) is an antioxidant enzyme and is copper dependent. It catalyses the dismutation of the damaging superoxide radical $\left(\mathrm{O}_{2}^{-}\right)$to molecular oxygen or hydrogen peroxide, the latter of which is in turn reduced to water by other enzymes. There are two types of SOD that use copper as a co-factor: (1) $\mathrm{Cu} / \mathrm{Zn}$ SOD, found in most animal cells; and (2) extracellular SOD, found in high levels in the lungs and in lesser amounts in plasma.

Of importance to IHD, superoxide radicals react with nitric oxide (NO) to produce the highly toxic molecule peroxynitrite, which contributes to oxidative and nitrosative damage. ${ }^{27} \mathrm{NO}$ acts to regulate endothelial function and is therefore important to vascular integrity. Copper deficiency, by reducing levels of SOD, can lead to reductions in NO, which in turn leads to reduced endothelial function, lower vasodilation and increased oxidative stress, all of these being hallmarks of atherosclerosis. ${ }^{28}$ Copper deficiency also reduces liver and plasma selenoglutathione peroxidase. ${ }^{29}$

Humans with diabetic nephropathy show significantly lower plasma levels of SOD, as well as an increased urinary copper excretion. ${ }^{28}$ Both of these factors may play a role in the increased incidence of IHD seen in diabetics. Thus, in individuals with diabetes and microalbuminuria, lower SOD and lower copper levels could promote IHD. Restoring copper levels through diet or supplementation may be an attractive, non-drug, therapeutic target in the treatment of diabetic nephropathy and the prevention of IHD.

Ceruloplasmin is an important copper-dependent protein and the major copper-carrying protein in the blood, carrying around $95 \%$ of circulating copper. ${ }^{30}$ The main function of ceruloplasmin is to oxidise ferrous iron $\left(\mathrm{Fe}^{2+}\right)$ to the less damaging ferric iron $\left(\mathrm{Fe}^{3+}\right)$; this allows transferrin, the major iron-transport protein, to be loaded with iron; thus, ceruloplasmin possesses antioxidant activity by preventing free radical damage via the Fenton reaction from free ferrous ions. Copper deficiency predisposes to hepatic iron over load, increased hepatic free radical formation and cirrhosis, likely via decreased ceruloplasmin in the blood..$^{19}$ Low hepatic copper levels appear to play a role in non-alcoholic fatty liver disease (NAFLD); patients with NAFLD have been noted to have lower copper levels, which are correlated with hepatic steatosis, fasting glucose and components of the metabolic syndrome. ${ }^{31-33}$ Rats made copper deficient through dietary copper restriction develop hepatic steatosis and insulin resistance. ${ }^{33}$ As insulin resistance may be the most important cause of IHD, its development via copper deficiency and low levels of ceruloplasmin may be a key mechanism through which insufficient copper promotes IHD.

\section{Glycation}

The glycosylation of proteins to form advanced glycation end-products (AGEs) is an important consequence 
of high blood glucose in diabetes and the metabolic syndrome. ${ }^{34}$ Rats fed the copper-deficient diet for 5 weeks developed copper deficiency as indicated by low copper concentrations in organs. Haemoglobin A1c, fructosamine and pentosidine, which are all AGEs, were all elevated compared with control rats. ${ }^{35}$ This result supports the hypothesis that dietary copper deficiency may manifest as an increased formation of AGEs, which in turn may manifest in vascular injury and increased susceptibility to IHD especially in diabetes and in those with metabolic syndrome.

\section{Ageing and mitochondria}

Ageing is an important risk factor for IHD, arguably the major risk factor. ${ }^{36}$ In ageing, an important defect is the increasing alteration of mitochondria and the subsequent decrease in their ability to generate energy, including in the heart and blood vessels. Several mechanisms may be responsible for decreased mitochondrial efficiency, one of which is damage to mitochondria via free radicals. ${ }^{37}$ Copper deficiency likely exacerbates mitochondrial damage via lower levels and activity of SOD. ${ }^{28} 3839$

Copper deficiency also elevates heme oxygenase in rats. ${ }^{40}$ Mitochondria isolated from rats on a copper-deficient diet have low levels of mitochondrial enzymes and significantly increased levels of hydrogen peroxide, indicating an increase in oxidative stress and decreased mitochondrial function. The inhibition of mitochondrial respiratory complex promotes the increased expression of heme oxygenase, which was elevated $85 \%$ in the hearts of copper-deficient rats.

Cytochrome $c$ activity is positively correlated with copper concentrations in copper-deficient and copper-sufficient rats, indicating another mechanism through which copper concentrations affect mitochondrial function. ${ }^{41} \mathrm{~A}$ decline in cytochrome $c$ oxidase (CCO) activity is characteristic of the ageing heart, and copper deficiency causes the same phenomenon. Reduced CCO activity in turn leads to cardiac hypertrophy. Caloric restriction may abrogate these changes, indicating that increased oxidative stress induced by copper deficiency may be behind these changes. Copper deficiency in experimental animals can be used as a model for studying the place of mitochondrial function in the ageing heart. ${ }^{41}$ Mitochondria of copper-deficient rats consume oxygen at a significantly lower rate than those of copper-sufficient rats; they have a lower membrane potential and an altered ATP synthase complex, indicating lower rates of energy production. ${ }^{42}$

\section{Copper deficiency and inflammation}

Rats fed low amounts of copper have increased inflammation whereas copper supplementation reduces inflammation. ${ }^{43}$ Copper deficiency leads to proinflammatory effects in neutrophils and in microvascular endothelial cells, promoting interactions between neutrophils and endothelium. ${ }^{44}$ As neutrophils may enter atherosclerotic lesions and contribute causally to atherosclerosis, copper deficiency may facilitate this process. ${ }^{45}$ Copper deficiency in rats also results in upregulation of the proinflammatory enzyme COX-2, suggesting that copper may increase inflammation independently of SOD activity. ${ }^{46}$ Copper deficiency in animals leads to increased hepatic expression of genes involved in inflammation and fibrinogenesis $^{47}$ and also increases nuclear factor kappa beta- $1 .{ }^{48}$ Copper supplementation in rats fed a copper-deficient, high-sucrose diet restores beta-cell function and reduces pancreatic low-grade inflammation (reverses hyperglycemia and reduces the infiltration of fat and IL-1 1 -expressing macrophages). ${ }^{49}$ Thus, copper has multiple actions for controlling inflammation including the rise in cereuloplasmin..$^{50} 51$

\section{Copper and myocardial tissue}

Copper deficiency in rodents leads to cardiac hypertrophy and to heart failure ${ }^{52}{ }^{53}$ Copper repletion leads to a rapid regression of cardiac hypertrophy and prevention of heart failure. ${ }^{54}$ Copper deficiency results in changes in myocardial gene expression, including upregulating inflammatory cytokines such as TNF-alpha. ${ }^{55}$ Other changes in gene expression involved factors that regulate cardiac contractility, calcium cycling and fibrosis, all of which might be the cause of altered cardiac function in copper-deficient mice. Additionally, copper deficiency reduces ATP synthase function, which may be the leading mechanism for inducing cardiac hypertrophy. ${ }^{5657}$ Copper repletion reverses these changes in heart tissue and may be the result of changes in gene expression in myocardial tissue. In copper depletion, lipid is deposited in myocardial tissue, along with swelling of mitochondria, cardiac hypertrophy and blunted response to a beta-adrenergic agonist, isoproterenol. Copper repletion reversed these changes, indicating that copper deficiency is an appealing target in cardiomyopathy. ${ }^{58}$ In a patient with mutations in Sco2, a copper-transport protein that delivers copper to CCO, copper-histidine resolves severe hypertrophic cardiomyopathy. ${ }^{59}$

\section{Copper, blood vessels and circulating blood cells}

Copper deficiency causes an exaggerated response of blood vessels to inflammatory stimuli. Increased neointima formation is seen in response to injury. In copper-deficient rats, neointima formation in response to injury increased some threefold compared with copper-sufficient rats; results indicated a close relation to lower levels of $\mathrm{Cu} / \mathrm{Zn}$-SOD. ${ }^{60}$

Lysyl oxidases are extracellular enzymes with copper cofactors and are used in the crosslinking of collagen and elastin; they provide tensile strength and elasticity to blood vessels. Absence of lysyl oxidases as seen in lysyl oxidase knockout mice leads to aortic aneurysms, cardiovascular dysfunction and death. ${ }^{61}$ Copper-deficient diets severely depress the activity of aortic lysyl oxidase, and copper administration rescues the inactivity, increasing lysyl oxidase activity some 20-fold; this suggests that dietary copper regulates aortic lysyl oxidase activity and determines aortic enzyme levels. ${ }^{62}$ 
Postcapillary venules show significantly greater leakage of proteins in response to histamine in copper-deficient rats. ${ }^{63}$ The response may be due to increased numbers of circulating mast cells. Nitric oxide promotes vasodilation of arterioles, and the vasodilation response is diminished in copper-deficient rats. Addition of $\mathrm{Cu} / \mathrm{Zn}$-SOD reverses this functional deficit, suggesting that the superoxide ion degrades NO in copper deficiency, while copper sufficiency restores the normal antioxidant function in blood vessels. Dietary copper is thus necessary for crucial microvascular functions that affect the regulation of peripheral blood flow and blood vessel integrity.

Bacterial lipopolysaccharide (endotoxin) is an inflammatory stimulus to blood vessels, causing dilation of arterioles. This response is increased in copper deficiency, and ibuprofen and diphenhydramine together blocked this response, indicating that the increased response to lipopolysaccharide with copper deficiency may involve increased sensitivity to the effects of histamine and arachidonic acid metabolites. ${ }^{64}$

Copper deficiency also affects erythrocytes, which are exposed to high concentrations of oxygen and contain heme iron, making them susceptible to oxidative stress. The erythrocytes of copper-deficient rats contain greater amounts of protein carbonyls, predominantly in the alpha and beta chains of the protein spectrin. This response is likely due to reduced amounts of $\mathrm{Cu} / \mathrm{Zn}-\mathrm{SOD} .^{65}$ Thus, copper deficiency increases oxidative damage in erythrocytes. Profound changes in erythrocyte morphology are seen in type 2o diabetes, a disease accompanied by an increased risk of heart disease. ${ }^{66}$

Platelet aggregation is increased in copper deficiency, and in copper-deficient rats the amount of fibrinogen in platelets is about fourfold higher than in controls while plasma fibrinogen is lower. The increased platelet aggregation in copper deficiency may be due to increased fibrinogen content of platelets. ${ }^{67}$

\section{Association between copper and heart disease}

In a group of 80 people including men and women who were scheduled for coronary angiography, leucocyte copper levels were measured and correlated to the degree of coronary artery disease, graded from no disease to severe disease. No significant differences were seen between patients in plasma copper or in lipid profiles; most plasma copper is found in the form of ceruloplasmin, which is an acute-phase reactant and is therefore not an accurate measure of body copper status. However, leucocyte copper was significantly associated with the degree of coronary artery disease, and this was independent of the subject's sex. The relationship between leucocyte copper and angiogram score was linear. ${ }^{68}$ This study suggests that low copper status leads to coronary artery disease and that leucocyte copper levels are better markers of risk than even lipid profiles (including total cholesterol, LDL, HDL and triglyceride). In another study, all the subjects of which were men having a coronary angiogram and without hypercholesterolemia, a significant and strong relation between leucocyte copper and degree of coronary artery disease was found again. ${ }^{69}$

Japanese who live in Japan as opposed to other countries are known to have a lower rate of IHD. The age-adjusted mortality rate for IHD in Okinawa is 26.41 for men and 14.18 for women; for Japanese in Brazil, the figures are 89.45 and 62.62 for men and women, respectively. Japanese men and women from Okinawa have leucocyte copper levels $33 \%$ higher than Japanese immigrants to Brazil. ${ }^{70}$ In each group, plasma copper levels did not differ. Leucocyte zinc was $19 \%$ higher in the Brazilian immigrant group, and the leucocyte $\mathrm{Zn} / \mathrm{Cu}$ ratio was $60 \%$ higher. Total cholesterol was similar in both Okinawan and Brazilian groups, but the Okinawan population had 20\% higher HDL. Okinawans have a high dietary copper intake due to the consumption of shellfish and seaweed, while Brazilians have a high dietary zinc intake, mainly from meat. As low copper and high zinc levels are associated with greater incidence of IHD, dietary intake may account for this increase. Further, leucocyte copper appears to be a better marker for copper status than does plasma copper.

In 40 people who died of coronary heart disease (32 with diagnosis of IHD, 8 with acute myocardial infarction), an analysis was made of trace elements in the aorta and compared with aortas of subjects who had died in accidents. Copper (as well as zinc and chromium) was significantly lower in the atherosclerotic plaques of abdominal aortas of patients vs controls. ${ }^{71}$

An analysis of postmortem human hearts revealed that a group with no history or subsequent finding of myocardial infarction had higher levels of copper (as well as zinc and magnesium) than the group who had died of a recent myocardial infarction. ${ }^{72}$ Similar findings of low copper in heart muscle in patients who died of IHD have been seen in other studies. ${ }^{73}$

\section{Effects of copper supplementation}

While copper is essential for antioxidant enzymes such as $\mathrm{SOD}$, it is also used in vitro to promote oxidation, and therefore has been suspected of promoting LDL oxidation in vivo. However, in humans who were supplemented with copper at 3 or $6 \mathrm{mg} /$ day, in addition to normal copper or copper-controlled diets, copper supplementation had no effect on LDL susceptibility to oxidation. ${ }^{74}$ Extended copper supplementation even at high intakes (up to $6 \mathrm{mg}$ per day) does not promote the susceptibility of LDL to oxidation. In fact, copper supplementation appears to protect against VLDL and LDL oxidation ${ }^{26}$ and erythrocyte oxidation. ${ }^{75}$

In young women given copper at $2 \mathrm{mg} /$ day for 8 weeks, ceruloplasmin and diamine oxidase increased, and no effect was seen in erythrocyte $\mathrm{Cu} / \mathrm{Zn}$-SOD. $\mathrm{F}_{2 \alpha}$-isoprostanes, a marker of oxidative stress, decreased by $39 \%$ while a marker for collagen crosslinks increased $62 \%{ }^{76}$ Therefore, in healthy adult women, copper supplementation appears to reduce oxidative stress and improve markers of copper function. Using the same protocol of $2 \mathrm{mg}$ /day 
of copper for 8 weeks, copper supplementation increased erythrocyte SOD and plasma ceruloplasmin. ${ }^{77}$ Changes in SOD were positively correlated with changes in HDL, and negatively correlated with changes in homocysteine.

Sixteen young women received copper supplementation at 0,3 or $6 \mathrm{mg} /$ day in a randomised crossover study at 4 weeks for each period of supplementation. The concentration of plasminogen activator inhibitor type 1 (PAI-1) decreased by $30 \%$ after supplementation leading the study's authors to conclude that "increased $\mathrm{Cu}$ intake could reduce the risk of CVD and atherosclerosis in man by promoting improved fibrinolytic capacity". ${ }^{78}$ PAI-1 is a marker and mediator of ageing and age-related disease. ${ }^{79}$ Indeed, humans with a null mutation for PAI-1 live approximately 10 years longer than those with normal PAI-1 genes. ${ }^{80}$ Thus, there is a link between copper status, IHD and lifespan.

\section{Is copper deficiency common?}

Plasma copper levels appear to be an inaccurate measure of copper status since ceruloplasmin is an acute-phase reactant that rises in illness and because plasma copper levels differ little between marginally copper-deficient and copper-sufficient subjects. ${ }^{68} 70$ Leucocyte copper may be the best measure of copper status, although this test is not commonly performed.

The RDA for copper is $0.9 \mathrm{mg} /$ day for adults for both men and women. The tolerable upper intake level is much higher, at $10 \mathrm{mg} /$ day for adults. In the 1980s, before a RDA was set, the suggested adequate intake range of copper was 2 to $3 \mathrm{mg}$ /day, but was subsequently lowered when it appeared that few people reach this range without copper supplements. ${ }^{81}$ It appears that the decrease in recommended copper intake was largely based on only one study of 11 healthy men. ${ }^{82}$ Copper requirements may, however, vary widely depending on health status, pregnancy, age, sex and other factors. Some studies show a minimum requirement at $1.3 \mathrm{mg} / \mathrm{d} .{ }^{81}$

In the EU and in the UK, half of the adult population consumes less than the recommended amount of copper, ${ }^{3}$ and in the USA and Canada, at least a quarter of the population consumes less than the estimated average requirement. And other studies have found that over $80 \%$ of the population may get less than the RDA $(0.9 \mathrm{mg} /$ day $)$ for copper from food. ${ }^{83}$ Around one-third of diets contain less than $1 \mathrm{mg}$ of copper daily and $61 \%$ contain less than $1.5 \mathrm{mg}$ with only $18 \%$ of diets exceeding $2 \mathrm{mg} /$ day. ${ }^{84}$ Thus, marginal copper deficiency may be quite common.

Foods that are high in copper include beef liver and shellfish, both of which are not commonly eaten in the typical Western diet. Other important sources of dietary copper include nuts, seeds, legumes and chocolate. Muscle meats typically contain a high ratio of zinc to copper, up to 50:1, and consumption of large amounts could result in copper imbalance. Organ meat, in contrast, has a zinc:copper ratio of about 2:1. Alan Gaby, $\mathrm{MD}$, stated that the "average copper content of fruits and

\section{Box 1 The harms of copper deficiency}

Increased cholesterol, decreased glucose tolerance and abnormal ECGs. $^{9}$

- Increased LDL and triglycerides and decreased HDL. ${ }^{15}$

- Increased susceptibility of lipoproteins and tissues to oxidation. ${ }^{11}$

- Increased apolipoprotein B. ${ }^{11}$

- Increased blood pressure. ${ }^{87}$

- Increased plasminogen activator inhibitor type $1 .^{78}$

- Increased early and advanced glycation end-products. ${ }^{35}$

- Increased inflammation ${ }^{43}$ and increase in the expression of genes involved in inflammation and fibrinogenesis. ${ }^{47}$

- Ultrastructural irregularities of elastin and abnormal endothelial cells, subendothelial space, collagen fibres and smooth muscle cells. $^{95}$

- Increased atherosclerosis. ${ }^{96}$

- Myelodysplastic syndrome. ${ }^{92}$

- Hepatic iron overload. ${ }^{19}$

- Fatty liver disease. ${ }^{31-334793}$

- Cardiac hypertrophy, ${ }^{54}$ cardiomyopathy. ${ }^{5358}$

- Optic neuropathy, myelopathy, anaemia and neutropenia. ${ }^{91}$

Atrial thrombosis, abnormal ECGs and sudden death. ${ }^{97}$

vegetables declined by $81 \%$ between the years 1940 and 2000 , presumably because of changes in farming methods that decreased the availability of copper in the soil". ${ }^{85}$ The reductions of copper in meat, cheese and other dairy products are also substantial $(-55 \%,-91 \%$ and $-97 \%$, respectively) ${ }^{86}$ Thus, our current dietary pattern as well as copper depletion in the food supply is undoubtedly contributing to the problem of copper deficiency.

Studies of copper supplementation have revealed that $62 \%$ of patients with moderate hypertension may be marginally copper deficient. ${ }^{87}$ Copper excretion increases during bedrest. ${ }^{88}$ Kidney disease, coeliac disease and bariatric surgery all increase the requirement for copper. ${ }^{89-91}$ The prevalence of these conditions in the population is high, and copper deficiency may masquerade as other conditions, such as myelodysplastic syndrome, and go unrecognised. ${ }^{92}$ The high consumption of fructose, a component of sucrose, that is, table sugar, induces copper deficiency in animals via impaired intestinal absorption. ${ }^{93}$ Since the average American consumes around 100 pounds of sugar annually, ${ }^{94}$ this may contribute to copper deficiency. Box 1 summarises the harms of copper deficiency. Table 1 summarises the benefits of copper supplementation in humans.

\section{DISCUSSION}

Copper deficiency creates or impacts virtually every risk factor of IHD, such as hypercholesterolemia and glucose tolerance, and can increase chronic inflammation and oxidative stress, which are also thought to be important factors in cardiovascular disease risk. Substantial evidence exists to show that marginal copper deficiency is common, which leads to the notion that insufficient copper levels, caused or exacerbated by insufficient dietary copper, may be involved in the promotion of IHD. Insufficient 
Table 1 Benefits of copper supplementation in humans

Study population Dose of copper Results

16 healthy young $\quad 3$ or $6 \mathrm{mg}$ of copper Significant increase in superoxide dismutase activity in red blood cells. Plasminogen activator inhibitor

women $^{78} \quad$ sulfate per day type 1 was significantly reduced $(p<0.05)$ by about $30 \%$ after supplementation with 6 mg copper per day 'Increased Cu intake could reduce the risk of CVD and atherosclerosis in man by promoting improved fibrinolytic capacity ${ }^{78}$

60 patients with $\quad 5 \mathrm{mg}$ of copper $\quad$ Blood pressure was significantly reduced in those treated with copper $(p<0.05)$ with no significant stable moderate sulfate per day changes in control patients

hypertension $^{87}$

It was estimated that $62 \%$ of study participants were marginally copper deficient

The study authors concluded that even mild copper deficiency could result in 'functional alteration in human blood pressure, 87

$\begin{array}{lll}73 \text { hyperlipidemic } & 5 \mathrm{mg} \text { of copper } & \text { Significant decreases in total cholesterol, triglycerides, LDL cholesterol and a slight increment in HDL } \\ \text { subjects }^{15} & \text { sulfate per day } & 38 \% \text { of the study participants were estimated to be marginally copper deficient }\end{array}$

CVD, cardiovascular disease; HDL, high-density lipoprotein; LDL, low-density lipoprotein.

body levels of copper may promote LDL oxidation, lower levels of crucial antioxidant enzymes, poorly functioning mitochondria and adverse changes to blood vessels, all of which may contribute to the genesis of IHD. Substantial human epidemiological evidence links copper deficiency with increased risk of IHD. Copper insufficiency is linked to NAFLD and the metabolic syndrome, and patients with these conditions are at higher risk of IHD. The major IHD risk, advancing age, may be linked with mitochondrial insufficiency, which is known to occur in ageing and which is also linked to low copper levels, which damage mitochondria. Copper supplementation in humans leads to lower levels of markers of oxidative stress, as well as to lower levels of PAI-1, an important risk factor for IHD. With reductions in copper levels in nearly all foods over the last several decades along with widespread adoption of ultra-processed food, low average copper consumption and extensive subclinical insufficiency or deficiency of copper may be more common than once thought.

While research and medical practice has focused almost exclusively on cholesterol and dietary saturated fat as IHD risk factors, we may have overlooked an exceedingly simple, plausible and widespread condition, copper deficiency, as one cause, perhaps even a major cause, of IHD. Increasing consumption of ultra-processed food, as well as a general avoidance of copper-rich foods, may play a role in widespread copper insufficiency and deficiency and therefore may be linked to IHD via copper. Copper in the diet or as supplementation has low toxicity, and an increased consumption of copper has the potential to reduce the population-wide incidence of IHD, heart failure and fatty liver disease. Copper deficiency as a link to increased risk of IHD deserves more attention from both clinicians and researchers.

\section{Contributors All authors contributed to the final manuscript.}

Funding The authors have not declared a specific grant for this research from any funding agency in the public, commercial or not-for-profit sectors.

Competing interests JJD is author of The Salt Fix. JHO'K has an ownership interest in CardioTabs. DM receives advertising revenue from supplements but not copper specifically.

Patient consent Not required.
Provenance and peer review Not commissioned; externally peer reviewed.

Open access This is an open access article distributed in accordance with the Creative Commons Attribution Non Commercial (CC BY-NC 4.0) license, which permits others to distribute, remix, adapt, build upon this work non-commercially, and license their derivative works on different terms, provided the original work is properly cited, appropriate credit is given, any changes made indicated, and the use is non-commercial. See: http://creativecommons.org/licenses/by-nc/4.0

\section{REFERENCES}

1. National Center for Health Statistics, 2015. Deaths and mortality. Available from: https://www.cdc.gov/nchs/fastats/deaths.htm

2. Siri-Tarino PW, Sun Q, Hu FB, et al. Meta-analysis of prospective cohort studies evaluating the association of saturated fat with cardiovascular disease. Am J Clin Nutr 2010;91:535-46.

3. Klevay LM. Is the Western diet adequate in copper? J Trace Elem Med Biol 2011:25:204-12.

4. Chambers A, Krewski D, Birkett N, et al. An exposure-response curve for copper excess and deficiency. J Toxicol Environ Health $B$ Crit Rev 2010;13(7-8):546-78.

5. Festa RA, Thiele DJ. Copper: an essential metal in biology. Curr Biol 2011;21:R877-R883.

6. Kelley DS, Daudu PA, Taylor PC, et al. Effects of low-copper diets on human immune response. Am J Clin Nutr 1995;62:412-6.

7. Nath R. Copper deficiency and heart disease: molecular basis, recent advances and current concepts. Int J Biochem Cell Biol 1997;29:1245-54.

8. Klevay LM. Ischemic heart disease as deficiency disease. Cell Mol Biol 2004;50:877-84.

9. Klevay LM. A major obstacle to becoming old. Clin Geriatr Med 1987;3:361-72.

10. Steinberg D. Low density lipoprotein oxidation and its pathobiological significance. J Biol Chem 1997;272:20963-6.

11. Rayssiguier $Y$, Gueux E, Bussiere L, et al. Copper deficiency increases the susceptibility of lipoproteins and tissues to peroxidation in rats. J Nutr 1993;123:1343-8.

12. Tainer JA, Getzoff ED, Richardson JS, et al. Structure and mechanism of copper, zinc superoxide dismutase. Nature 1983;306:284-7.

13. Mazur A, Gueux E, Bureau I, et al. Copper deficiency and lipoprotein oxidation. Atherosclerosis 1998;137:443-5.

14. Kim S, Chao PY, Allen KG. Inhibition of elevated hepatic glutathione abolishes copper deficiency cholesterolemia. Faseb J 1992;6:2467-71.

15. Alarcon-Corredor OM, Guerrero $\mathrm{Y}$, Ramirez de Fernandez M, et al. [Effect of copper supplementation on lipid profile of Venezuelan hyperlipemic patients]. Arch Latinoam Nutr 2004;54:413-8.

16. Rojas-Sobarzo L, Olivares M, Brito A, et al. Copper supplementation at $8 \mathrm{mg}$ neither affects circulating lipids nor liver function in apparently healthy Chilean men. Biol Trace Elem Res 2013;156:1-4.

17. Fields $M$, Lewis CG. Level of dietary iron, not type of dietary fat, is hyperlipidemic in copper-deficient rats. J Am Coll Nutr 1999;18:353-7.

18. Sullivan J. Iron and the sex difference in heart disease risk. The Lancet 1981;317:1293-4. 
19. Thackeray EW, Sanderson SO, Fox JC, et al. Hepatic iron overload or cirrhosis may occur in acquired copper deficiency and is likely mediated by hypoceruloplasminemia. $J$ Clin Gastroenterol 2011:45:153-8.

20. Fields M, Lewis CG. Hepatic iron overload may contribute to hypertriglyceridemia and hypercholesterolemia in copper-deficient rats. Metabolism 1997;46:377-81.

21. Videt-Gibou D, Belliard S, Bardou-Jacquet E, et al. Iron excess treatable by copper supplementation in acquired aceruloplasminemia: a new form of secondary human iron overload? Blood 2009;114:2360-1.

22. Klevay LM. Iron overload can induce mild copper deficiency. J Trace Elem Med Biol 2001;14:237-40.

23. Fields M, Lewis CG, Lure MD, et al. The severity of copper deficiency can be ameliorated by deferoxamine. Metabolism 1991;40:105-9.

24. Klevay LM, Hyg. SD. Hypercholesterolemia in rats produced by an increase in the ratio of zinc to copper ingested. Am J Clin Nutr 1973;26:1060-8

25. Klevay LM, Inman L, Johnson LK, et al. Increased cholesterol in plasma in a young man during experimental copper depletion. Metabolism 1984;33:1112-8.

26. Jones AA, DiSilvestro RA, Coleman M, et al. Copper supplementation of adult men: effects on blood copper enzyme activities and indicators of cardiovascular disease risk. Metabolism 1997:46:1380-3.

27. Noiri $\mathrm{E}$, Nakao A, Uchida $\mathrm{K}$, et al. Oxidative and nitrosative stress in acute renal ischemia. Am J Physiol Renal Physiol 2001;281:F94 8-F957.

28. Al-Bayati MA, Jamil DA, Al-Aubaidy HA. Cardiovascular effects of copper deficiency on activity of superoxide dismutase in diabetic nephropathy. N Am J Med Sci 2015;7:41-6.

29. Olin KL, Walter RM, Keen CL. Copper deficiency affects selenoglutathione peroxidase and selenodeiodinase activities and antioxidant defense in weanling rats. Am J Clin Nutr 1994;59:654-8.

30. Altamura C, Squitti R, Pasqualetti P, et al. Ceruloplasmin/ transferrin system is related to clinical status in acute stroke. Stroke 2009;40:1282-8

31. Mendoza M, Caltharp S, Song M, et al. Low hepatic tissue copper in pediatric nonalcoholic fatty liver disease. J Pediatr Gastroenterol Nutr 2017;65:89-92.

32. Morrell A, Tallino S, Yu L, et al. The role of insufficient copper in lipid synthesis and fatty-liver disease. IUBMB Life 2017;69:263-70.

33. Aigner $\mathrm{E}$, Strasser $\mathrm{M}$, Haufe $\mathrm{H}$, et al. A role for low hepatic copper concentrations in nonalcoholic fatty liver disease. $\mathrm{Am} \mathrm{J}$ Gastroenterol 2010;105:1978-85.

34. Goldin Aet al. Advanced glycation end products: sparking the development of diabetic vascular injury. Circulation 2006;114:597-605.

35. Saari JT, Dahlen GM. Early and advanced glycation end-products are increased in dietary copper deficiency. J Nutr Biochem 1999;10:210-4.

36. Lakatta EG, Levy D. Arterial and cardiac aging: major shareholders in cardiovascular disease enterprises: part I: aging arteries: a "set up" for vascular disease. Circulation 2003;107:139-46.

37. Ames BN. Delaying the mitochondrial decay of aging. Ann NY Acad Sci 2004;1019:406-11.

38. Johnson WT, Johnson LAK, Lukaski HC. Serum superoxide dismutase 3 (extracellular superoxide dismutase) activity is a sensitive indicator of Cu status in rats. J Nutr Biochem 2005;16:682-92.

39. DiSilvestro RA. Influence of copper intake and inflammation on rat serum superoxide dismutase activity levels. J Nutr 1988;118:474-9.

40. Johnson WT, DeMars LCS. Increased heme oxygenase- 1 expression during copper deficiency in rats results from increased mitochondrial generation of hydrogen peroxide. J Nutr 2004;134:1328-33.

41. Johnson WT, Newman SM. Copper deficiency: a potential model for determining the role of mitochondria in cardiac aging. Age 2003;26:19-28.

42. Chen X, Jennings DB, Medeiros DM. Impaired cardiac mitochondrial membrane potential and respiration in copper-deficient rats. $J$ Bioenerg Biomembr 2002;34:397-406.

43. Denko CW, Petricevic M, Whitehouse MW. Inflammation in relation to dietary intake of zinc and copper. Int J Tissue React 1981;3:73-6.

44. Lominadze D, Saari JT, Percival SS, et al. Proinflammatory effects of copper deficiency on neutrophils and lung endothelial cells. Immuno Cell Biol 2004;82:231-8.

45. Soehnlein O. Multiple roles for neutrophils in atherosclerosis. Circ Res 2012:110:875-88.

46. Schuschke DA, Adeagbo AS, Patibandla PK, et al. Cyclooxygenase-2 is upregulated in copper-deficient rats. Inflammation 2009;32:333-9.
47. Tallino S, Duffy M, Ralle M, et al. Nutrigenomics analysis reveals that copper deficiency and dietary sucrose up-regulate inflammation, fibrosis and lipogenic pathways in a mature rat model of nonalcoholic fatty liver disease. J Nutr Biochem 2015;26:996-1006.

48. Klaahsen D, Ricklefs K, Medeiros DM. Differential expression of genes involved with apoptosis, cell cycle, connective tissue proteins, fuel substrate utilization, inflammation and mitochondrial biogenesis in copper-deficient rat hearts: implication of a role for Nfkb1. J Nutr Biochem 2007;18:719-26.

49. Weksler-Zangen S, Jörns A, Tarsi-Chen L, et al. Dietary copper supplementation restores $\beta$-cell function of cohen diabetic rats: a link between mitochondrial function and glucose-stimulated insulin secretion. Am J Physiol Endocrinol Metab 2013;304:E1023-E1034.

50. Milanino R, Velo GP. Multiple actions of copper in control of inflammation: studies in copper-deficient rats. Agents Actions Suppl 1981;8:209-30.

51. Denko CW. Protective role of ceruloplasmin in inflammation. Agents Actions 1979;9:333-6.

52. Medeiros DM. Perspectives on the role and relevance of copper in cardiac disease. Biol Trace Elem Res 2017;176:10-19.

53. Li Y, Wang L, Schuschke DA, et al. Marginal dietary copper restriction induces cardiomyopathy in rats. J Nutr 2005;135:2130-6.

54. Zhou Z, Johnson WT, Kang YJ. Regression of copper-deficient heart hypertrophy: reduction in the size of hypertrophic cardiomyocytes. $J$ Nutr Biochem 2009;20:621-8.

55. Elsherif L, Jiang Y, Saari JT, et al. Dietary copper restriction-induced changes in myocardial gene expression and the effect of copper repletion. Exp Biol Med 2004;229:616-22.

56. Medeiros DM, Jennings $\mathrm{D}$. Role of copper in mitochondrial biogenesis via interaction with ATP synthase and cytochrome $c$ oxidase. J Bioenerg Biomembr 2002;34:389-95.

57. Chao JCJ, Medeiros DM, Davidson J, et al. Low levels of ATP synthase and cytochrome $c$ oxidase subunit peptide from hearts of copper-deficient rats are not altered by the administration of dimethyl sulfoxide. J Nutr 1994;124:789-803.

58. Elsherif L, Wang L, Saari JT, et al. Regression of dietary copper restriction-induced cardiomyopathy by copper repletion in mice. $J$ Nutr 2004;134:855-60.

59. Freisinger P, Horvath R, Macmillan C, et al. Reversion of hypertrophic cardiomyopathy in a patient with deficiency of the mitochondrial copper binding protein Sco2: Is there a potential effect of copper? J Inherit Metab Dis 2004;27:67-79.

60. Lucca JJD, Saari JT, Falcone JC, et al. Neointima formation in the rat carotid artery is exacerbated by dietary copper deficiency. Exp Biol Med 2002:227:487-91.

61. Maki JMet al. Inactivation of the lysyl oxidase gene Lox leads to aortic aneurysms, cardiovascular dysfunction, and perinatal death in mice. Circulation 2002:106:2503-9.

62. Harris ED. Copper-induced activation of aortic lysyl oxidase in vivo Proc Natl Acad Sci U S A 1976;73:371-4

63. Schuschke DA. Dietary copper in the physiology of the microcirculation. J Nutr 1997;127:2274-81.

64. Schuschke DA, Saari JT, Miller FN. Arteriolar dilation to endotoxin is increased in copper-deficient rats. Inflammation 1997;21:45-53.

65. Sukalski KA, LaBerge TP, Johnson WT. In vivo oxidative modification of erythrocyte membrane proteins in copper deficiency. Free Radic Biol Med 1997;22:835-42.

66. Pretorius E, Bester J, Vermeulen N, et al. Poorly controlled type 2 diabetes is accompanied by significant morphological and ultrastructural changes in both erythrocytes and in thrombingenerated fibrin: implications for diagnostics. Cardiovasc Diabetol $2015 ; 14: 30$

67. Lominadze D, Saari J, Miller F, et al. Platelet aggregation and adhesion during dietary copper deficiency in rats. Thromb Haemost 1996;76:630-4

68. Mielcarz G, Howard AN, Mielcarz B, et al. Leucocyte copper, a marker of copper body status is low in coronary artery disease. $J$ Trace Elem Med Biol 2001;15:31-5.

69. Kinsman GD, Howard AN, Stone DL, et al. Studies in copper status and atherosclerosis. Biochem Soc Trans 1990;18:1186-8.

70. Mielcarz GW, Howard AN, Williams NR. Copper and zinc status as a risk factor for ischemic heart disease: a comparison between japanese in brazil and Okinawa. The Journal of Trace Elements in Experimental Medicine 1997:10:29-35.

71. Vlad M, Caseanu E, Uza G, et al. Concentration of copper, zinc, chromium, iron and nickel in the abdominal aorta of patients deceased with coronary heart disease. J Trace Elem Electrolytes Health Dis 1994;8:111-4.

72. Zama N, Towns RLR. Cardiac copper, magnesium, and zinc in recent and old myocardial infarction. Biol Trace Elem Res 1986;10:201-8. 
73. Chipperfield B, Chipperfield JR. Differences in metal content of the heart muscle in death from ischemic heart disease. Am Heart $J$ 1978;95:732-7.

74. Turley E, McKeown A, Bonham MP, et al. Copper supplementation in humans does not affect the susceptibility of low density lipoprotein to in vitro induced oxidation (FOODCUE project). Free Radic Biol Med 2000;29:1129-34.

75. Rock E, Mazur A, O'connor JM, et al. The effect of copper supplementation on red blood cell oxidizability and plasma antioxidants in middle-aged healthy volunteers. Free Radic Biol Med 2000;28:324-9.

76. DiSilvestro RA, Selsby J, Siefker K. A pilot study of copper supplementation effects on plasma F2alpha isoprostanes and urinary collagen crosslinks in young adult women. J Trace Elem Med Biol 2010;24:165-8.

77. DiSilvestro RA, Joseph EL, Zhang W, et al. A randomized trial of copper supplementation effects on blood copper enzyme activities and parameters related to cardiovascular health. Metabolism 2012;61:1242-6.

78. Bügel S, Harper A, Rock E, et al. Effect of copper supplementation on indices of copper status and certain CVD risk markers in young healthy women. Br J Nutr 2005;94:231-6.

79. Vaughan DE, Rai R, Khan SS, et al. Plasminogen activator Inhibitor-1 is a marker and a mediator of enescence. Arterioscler Thromb Vasc Biol 2017;37:1446-52.

80. Khan SS, Shah SJ, Klyachko E, et al. A null mutation in SERPINE1 protects against biological aging in humans. Sci Adv 2017;3:eaao1617.

81. Turnlund JR. Copper nutriture, bioavailability, and the influence of dietary factors. J Am Diet Assoc 1988;88:303-8.

82. Turnlund JR, Keen CL, Smith RG. Copper status and urinary and salivary copper in young men at three levels of dietary copper. Am J Clin Nutr 1990;51:658-64.

83. Georgopoulos PG, Wang SW, Georgopoulos IG, et al. Assessment of human exposure to copper: a case study using the NHEXAS database. J Expo Sci Environ Epidemiol 2006;16:397-409.

84. Klevay LM. Trace element and mineral nutrition in ischemic heart diseaseclinical nutrition of the essential trace elements and minerals.
In: Bogden JD, Klevay LM, eds. Nutrition $\diamond$ and $\diamond$ Health. Totowa: Humana PressNJ, 2000.

85. New York Times, 2015. Available from: http:// wwwnytimescom/2015/11/01/magazine/bread-is-brokenhtml? $r=1$

86. Thomas D. The mineral depletion of foods available. Nutr Health 2007;19:21-55

87. Alarcon OM, Guerrero Y, Ramirez de Fernandez M, et al. [Effect of cooper supplementation on blood pressure values in patients with stable moderate hypertension]. Arch Latinoam Nutr 2003:53:271-6.

88. Heacox HN, Gillman PL, Zwart SR, et al. Excretion of zinc and copper increases in men during 3 weeks of bed rest, with or without artificial gravity. J Nutr 2017;147:1113-20.

89. Brown EA, Sampson B, Muller BR, et al. Urinary iron loss in the nephrotic syndrome - an unusual cause of iron deficiency with a note on urinary copper losses. Postgrad Med J 1984;60:125-8.

90. Halfdanarson TR, Kumar N, Hogan WJ, et al. Copper deficiency in celiac disease. J Clin Gastroenterol 2009:43:162-4.

91. Yarandi SS, Griffith DP, Sharma R, et al. Optic neuropathy, myelopathy, anemia, and neutropenia caused by acquired copper deficiency after gastric bypass surgery. J Clin Gastroenterol 2014;48:862-5.

92. Gregg XT, Reddy V, Prchal JT. Copper deficiency masquerading as myelodysplastic syndrome. Blood 2002;100:1493-5.

93. Song M, Schuschke DA, Zhou Z, et al. High fructose feeding induces copper deficiency in Sprague-Dawley rats: a novel mechanism for obesity related fatty liver. J Hepatol 2012;56:433-40.

94. DiNicolantonio JJ, Lucan SC. The wrong white crystals: not salt but sugar as aetiological in hypertension and cardiometabolic disease. Open Heart 2014;1:e000167.

95. Hunsaker H, Morita M, Allen K. Marginal copper deficiency in rats aortal morphology of elastin and cholesterol values in firstgeneration adult males. Atherosclerosis 1984;51:1-19.

96. Hamilton IM, Gilmore WS, Strain JJ. Marginal copper deficiency and atherosclerosis. Biol Trace Elem Res 2000;78:179-90.

97. Klevay LM. Atrial thrombosis, abnormal electrocardiograms and sudden death in mice due to copper deficiency. Atherosclerosis 1985;54:213-24 